\title{
Effect of Pre-deformation on Grain Ultrafining by Intercritical Deformation in Low-Carbon Microalloyed Steels
}

\author{
Ba $\mathrm{Li}^{1} \cdot$ Qing-You Liu ${ }^{1} \cdot$ Shu-Jun Jia ${ }^{1} \cdot \mathrm{Yi} \mathrm{Ren}^{2} \cdot$ Bing Wang ${ }^{1}$ \\ Received: 14 March 2018/Revised: 7 April 2018/Published online: 22 June 2018 \\ (C) The Chinese Society for Metals and Springer-Verlag GmbH Germany, part of Springer Nature 2018
}

\begin{abstract}
In this study, the effect of pre-deformation at recrystallization and non-recrystallization zone on the grain ultrafining by the subsequent intercritical deformation (ID) was investigated on low-carbon microalloyed steel. The results showed that ultrafine grain microstructure with an average size of $\sim 1.0 \mu \mathrm{m}$ was fabricated through pre-deformation in the recrystallization zone followed by ID. When pre-deformed at the non-recrystallization zone prior to ID, the grain size increased to $1.6 \mu \mathrm{m}$ with a heterogeneous distribution along with the well-developed dynamic recovery of ferrite. The grain ultrafining mechanism was attributed to the combined action of the deformation-induced ferrite transformation and the continuous dynamic recrystallization. In particular, the continuous dynamic recrystallization process during ID occurred on the pro-eutectoid ferrite as a result of the subgrain rotation mechanism and the absorbing dislocations mechanism.
\end{abstract}

Keywords Low-carbon microalloyed steels · Intercritical deformation · Ultrafine grain · Continuous dynamic recrystallization $\cdot$ Deformation-induced ferrite transformation

\section{Introduction}

Thermomechanical control process (TMCP) technology has been widely used for steel production applied in fields of shipbuilding, pipeline and building construction, etc. $[1,2]$. During TMCP, five zones including austenite recrystallization zone (RZ), austenite non-recrystallization zone (NRZ), intercritical zone (IZ) (i.e., ferrite + austenite two-phase zone), ferrite warm-deformation zone (WZ) and ferrite cold-deformation zone $(\mathrm{CZ})$ can be utilized to control the microstructure of the steels [3-6]. Deformation in $\mathrm{WZ}$ or $\mathrm{CZ}$ in conjunction with the subsequent heat treatment can refine the grain size to a few hundred nanometers; nevertheless, this method is always restricted by the low deformation temperature and very large reduction [7, 8]. Additionally, the degree of grain

Available online at http://link.springer.com/journal/40195

$\mathrm{Ba} \mathrm{Li}$

balicugb@sina.com

1 Central Iron and Steel Research Institute, Beijing 100081, China

2 Iron and Steel Research Institute, Ansteel Group Co., Ltd., Anshan 114009, China refinement for deformation in RZ, NRZ and even RZ + $\mathrm{NRZ}$ is limited because of the relatively high deformation temperature [6]. To date, a large number of investigations are focused on the approach, in which ultrafine grains can be produced due to the deformation-induced ferrite transformation (DIFT) resulting from heavy deformation between $A_{e 3}$ and $A_{r 3}$ in NRZ [9-11].

Regarding the grain refinement by DIFT, the microstructure evolution is seriously affected by the predeformation zone prior to DIFT [11]. On the one hand, the refinement of austenite grains by pre-deformation in RZ can accelerate the onset of DIFT [12]. On the other hand, the decrease in the pancaked-austenite grain thickness due to the pre-deformation in the NRZ can refine the grain size of the phase-transformed ferrite by subsequent controlled cooling [13]. Moreover, Bae et al. [14] demonstrated that the volume fraction of the deformation-induced ferrite (DIF) nucleation by pre-deformation is higher in the NRZ than in the RZ.

As compared with DIFT, unfortunately, deformation in IZ, i.e., intercritical deformation (ID), is still far from being understood due to its complicated structure transformation, although it has been confirmed that steels treated by ID technology exhibit more excellent low-temperature toughness than that produced by DIFT technology, which 
is mainly due to the achievement of grain ultrafining [15-17]. With the development of the rolling technology, the ID can be performed under relatively low deformation temperature for steels manufacturing [18]. Several studies revealed the mechanism of grain refinement with respect to ID through one-pass hot compression or torsion tests with large strain [19-26]. According to these investigations, there are two opinions regarding the mechanism of the grain ultrafining during ID. One is the continuous dynamic recrystallization (cDRX) of pro-eutectoid ferrite [19-22], and the other is the interacted result of the ferrite cDRX and austenite DIFT [3, 24-26]. Therefore, the mechanism of grain refinement of ID was still controversial and indistinct, especially introducing the pre-deformation before ID. Accordingly, in this paper, pre-deformation in RZ and NRZ and followed by ID was carried out on lowcarbon microalloyed steel, respectively. Refined microstructures were comparatively investigated in detail to reveal the mechanism of grain refinement.

\section{Experimental}

In this work, a commercial high-grade pipeline steel was utilized, and the cylindrical tube was $20 \mathrm{~mm}$ in length and $8 \mathrm{~mm}$ in diameter. The steel's chemical composition was C: 0.04, Si: 0.28, Mn: 1.54, P: 0.011, S: 0.002, Nb: 0.062, Ti: 0.014, Mo: 0.14, Ni: 0.29, Cr: 0.25, Fe: bal (in wt\%). The simulated TMCP was conducted using a Gleeble 1500 simulator, as illustrated in Fig. 1a. First, the steel specimens were soaked at $1180{ }^{\circ} \mathrm{C}$ for $300 \mathrm{~s}$ with a heating rate of $10{ }^{\circ} \mathrm{C} / \mathrm{s}$. Then, a uniaxial compressive pre-deformation of $30 \%$ reduction $(\varepsilon=0.36)$ at $980{ }^{\circ} \mathrm{C}$ (in RZ) and $820{ }^{\circ} \mathrm{C}$ (in NRZ) was then performed. Prior to the second-pass deformation, the $\mathrm{A}_{\mathrm{r} 3}$ was measured using a thermal dilatometer and using the same process as in the pre-deformation (Fig. 1b); the cooling rate was $5{ }^{\circ} \mathrm{C} / \mathrm{s}$. Thus, the

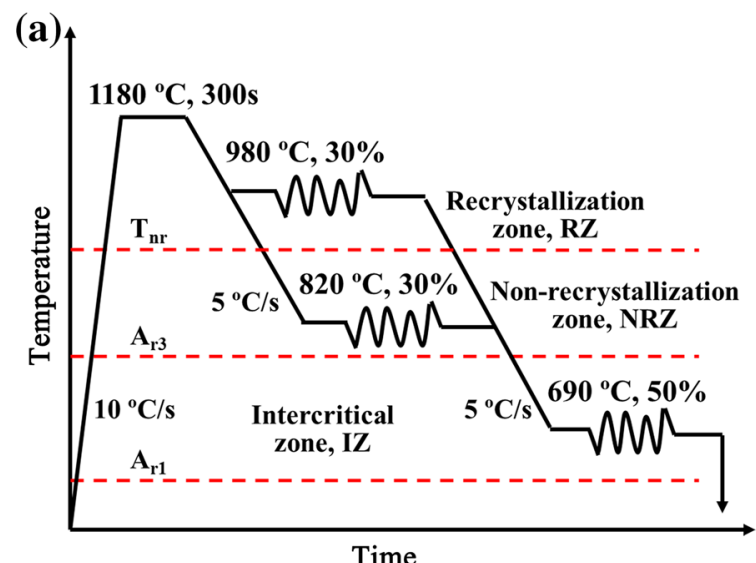

Time
$\mathrm{A}_{\mathrm{r} 3}$ measured for the case of pre-deformation at 980 and $820{ }^{\circ} \mathrm{C}$ was 720 and $728^{\circ} \mathrm{C}$, respectively. This took into account the effect of deformation on the phase transformation temperature. Then, the two specimens were continuously cooled to $690{ }^{\circ} \mathrm{C}\left(\mathrm{A}_{\mathrm{r} 3}-30^{\circ} \mathrm{C}\right)$ with the cooling rate of $5{ }^{\circ} \mathrm{C} / \mathrm{s}$ and a $50 \%$ reduction $(\varepsilon=0.69)$ was performed. The strain rate of the two-stage deformations was $1 \mathrm{~s}^{-1}$. After deformation, the specimens were immediately cooled using water. For comparison, the specimens before deformation at $690{ }^{\circ} \mathrm{C}$ were also prepared by water cooling. The observation of microstructure was carried out at the center on a cross section of the compressed specimens using optical microscopy (OM, MEF-4 M) and scanning electron microscopy (SEM, S-4300). The specimens for $\mathrm{OM}$ and SEM analysis were ground, polished and etched in a $4 \%$ nital solution. The initial austenite before pre-deformation was observed in situ using high-temperature metallography (VL2000DX-SVF17SP), while the original austenite after pre-deformation was hot-etched using supersaturated picric acid with sodium dodecylbenzene sulfonate. Electron back-scattered diffraction (EBSD, Nordlys $\mathrm{F}+$ ) was then adopted to distinguish the crystallography of steel specimens. The EBSD observation specimens were prepared by a thin foils with a diameter of $3 \mathrm{~mm}$ and $80-100 \mu \mathrm{m}$ thickness. Then, they were electropolished by a twin-jet electropolisher in an electrolyte with $6 \%$ perchloric acid and 94\% methanol below $-30{ }^{\circ} \mathrm{C}$.

\section{Results and Discussion}

\subsection{Microstructure Evolution During Two-Stage Deformation}

The two specimens, which were observed in situ using high-temperature metallography, have the same grains

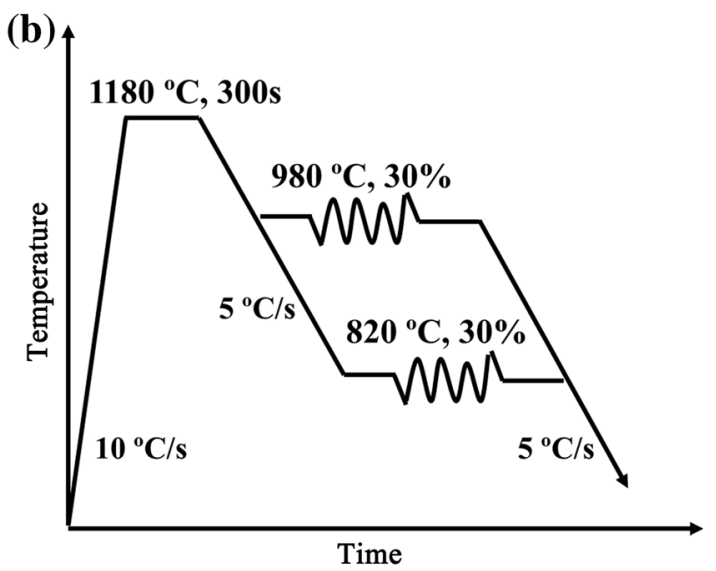

Fig. 1 Schedule of: a experimental, $\mathbf{b}$ thermal dilatometer test 
sizes of the original austenite before pre-deformation (Fig. 2a, b). In other words, the effect of the initial grain size on the subsequent deformation can be neglected. Figure $2 \mathrm{c}-\mathrm{h}$ displays the microstructure before and after ID, which helps to understand the microstructure evolution during the two-stage deformation. After pre-deformation at $980{ }^{\circ} \mathrm{C}$ (in RZ), the equiaxial fine original austenite produced by DRX of austenite was obtained as illustrated in Fig. 2c. By lowering the pre-deformation temperature to $820^{\circ} \mathrm{C}$ (in NRZ), the original austenite with pancaked morphology and relatively large size was acquired as indicated in Fig. 2d.

When cooling to $690{ }^{\circ} \mathrm{C}$ (in IZ), undercooled austenite became unstable leading to phase-transforming to pro-eutectoid ferrite on the grain boundaries as well as the deformation bands. A two-phase microstructure mixed with pro-eutectoid ferrite and martensite was formed after water quenching. As a result, the microstructure based on pre-deformation at $980{ }^{\circ} \mathrm{C}$ was refined and presented equiaxial and homogeneous distribution (as shown in Fig. 2e), whereas the pancaked grains with uneven size were formed on the basis of pre-deformation at $820{ }^{\circ} \mathrm{C}$ (as exhibited in Fig. 2f). The difference of the two-phase microstructure with respect to the two specimens could be explained as follows. After pre-deforming in RZ, the equiaxed and refined austenite was acquired, which provide a high volume fraction of grain boundaries, increasing the nucleation sites for the following pro-eutectoid transformation when cooling to IZ. Then, the pro-eutectoid ferrite nucleated and grew on grain boundaries leading to the refinement of the entire microstructure. In the case of predeformation in NRZ, the larger austenite grains were pancaked and produced many deformation bands inside. It has been well known that not all deformation bands obtained in NRZ can be an effective nucleation sites. Also, even if the number of deformation zones has reached the limit, there are still $10 \%$ of the austenite grains having very few deformation bands. [6]. In this case, when cooling to IZ, the content of pro-eutectoid ferrite transformed on grain boundaries and deformation bands was found to be relatively small, while the deformed austenite with fewer deformation bands transformed to the large and pancaked martensite.

After ID at $690{ }^{\circ} \mathrm{C}$, both specimens deformed at 980 and $820{ }^{\circ} \mathrm{C}$ were dramatically refined (as indicated in Fig. $2 \mathrm{~g}$, $\mathrm{h}$ ), showing the incidence of microstructural reconstitution. Also, the formation of ultrafine fibrous grain structure (as displayed in Fig. 2h) suggested that the reconstitution process was incomplete.

\subsection{Stress-Strain Curve Analysis}

As displayed in Fig. 3), the stress-strain curves exhibit significant softening in the second-stage deformation, which confirms the restoration phenomenon. It has been reported that both DIFT and cDRX processes may occur during ID after a large single-pass deformation [24-26]. For further examination, the second derivative of the second-stage deformation stresses, which is called the "double-differentiation method," was calculated on the basis of the stress-strain curves. In this case, the stationary point on the double-differentiation curve indicates the critical stress of the restoration occurrence [27]. Regarding DIFT, eightorder polynomials are commonly used to fit the flow curve. When there is more than one softening process, high-order polynomials need to be selected [27, 28]. Figure $2 b$, c illustrates the impacts of the order on the values of the critical strains. When the order of polynomials was increased to 16 , the second minima appeared, indicating that two restoration processes might have occurred during ID. Jonas et al. [28] re-analyzed the 63 published flow curves by high-order polynomial fitting demonstrating that the first minima are related to the initiation of dynamic transformation, while the second one corresponds with the dynamic recrystallization process. Therefore, the first and second minima (as illustrated in Fig. 2b) correspond to the initiation of DIFT and cDRX, respectively. It means that the critical stress of DIFT was smaller than cDRX during ID based on pre-deformation at $980{ }^{\circ} \mathrm{C}$. When the predeformation temperature decreased to $820^{\circ} \mathrm{C}$, as exhibited in Fig. 2c, the opposite was observed; the critical stress of cDRX was smaller than that of DIFT.

\subsection{EBSD Analysis}

Figure $4 \mathrm{a}, \mathrm{b}$ shows the colored inverse pole figure (IPF) orientation maps of the two specimens after ID at $690{ }^{\circ} \mathrm{C}$. As shown in Fig. 4a for the specimen pre-deformed at $980{ }^{\circ} \mathrm{C}$, the various colors describe a uniform distribution of the ultrafine grains as well as the grain orientation, while for the specimen pre-deformed at $820^{\circ} \mathrm{C}$ in Fig. $4 \mathrm{~b}$, the pancaked grains with relatively large size and single color are discovered. Figure $4 \mathrm{c}$ displays the misorientation angle distribution of the two specimens. The proportion of low angle grain boundary (LAGB) of the specimen pre-deformed at $980{ }^{\circ} \mathrm{C}$ was found to be significantly higher than that at $820^{\circ} \mathrm{C}$ (marked by dark gray). However, the proportion of high angle grain boundary (HAGB) was just the opposite (marked by light gray). Interestingly, the amount of HAGBs gradually increased with an increase in the misorientation angle. 

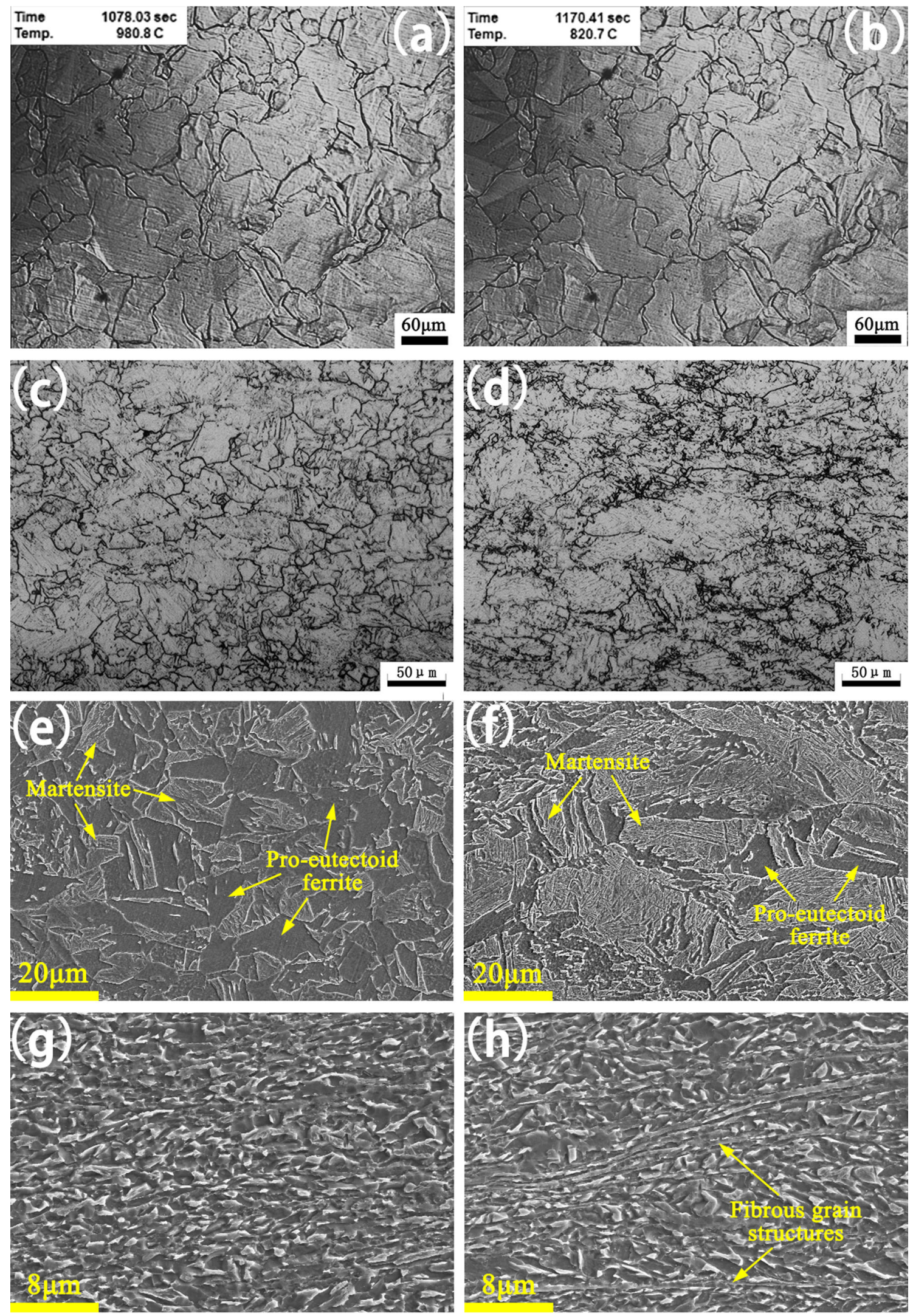

Fig. 2 Microstructure of specimens pre-deformed at 980 and $820^{\circ} \mathrm{C}$ : a, b initial austenite before pre-deformation, c, d OM micrographs of original austenite after pre-deformation, e, f SEM micrographs before intercritical deformation (ID), $\mathbf{g}, \mathbf{h}$ after ID at $690{ }^{\circ} \mathrm{C}$, respectively 

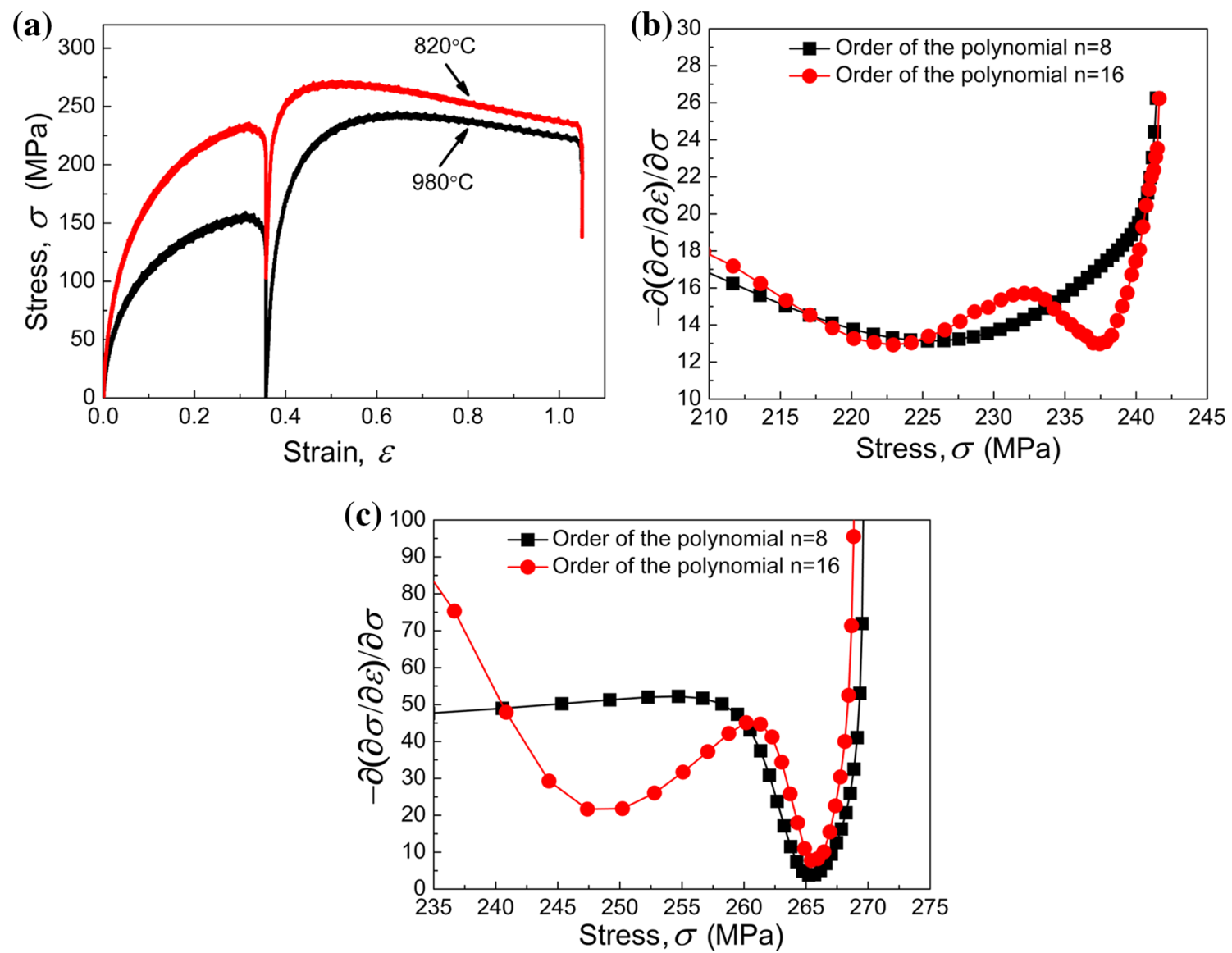

Fig. 3 a Stress-strain curve. Effect of order on the values of the critical strains for the specimens pre-deformed at: b $980{ }^{\circ} \mathrm{C}$, c $820{ }^{\circ} \mathrm{C}$

The grain size distribution of the two specimens illustrated in Fig. 4d indicates that the grain size smaller than $2.7 \mu \mathrm{m}$ increased dynamically in the specimen that predeformed at $980^{\circ} \mathrm{C}$, unlike in the specimen treated at $820^{\circ} \mathrm{C}$. The effective grain size (EGS) of the specimens was much smaller $(\sim 1.0 \mu \mathrm{m})$ at $980{ }^{\circ} \mathrm{C}$ than at $820{ }^{\circ} \mathrm{C}$ $(1.6 \mu \mathrm{m})$. Moreover, the average grain size before ID was determined from the SEM micrographs using the ImagePro Plus software (Fig. 2e, f). For the specimen pre-deformed at $980{ }^{\circ} \mathrm{C}$, the average grain size of the pro-eutectoid ferrite and martensite (i.e., the original austenite) was 5.4 and $7.1 \mu \mathrm{m}$, respectively. The specimens pre-deformed at $820{ }^{\circ} \mathrm{C}$ had grain sizes of $5.0 \mu \mathrm{m}$ and $14.7 \mu \mathrm{m}$, respectively. A comparison of the grain size before and after the ID of the two specimens indicated that the grain size smaller than $2.7 \mu \mathrm{m}$ was largely dynamically formed due to the significant refinement of the grain size.

For an image comparison, these grains were chosen and represented in blue as shown in Fig. 4e, f. It is evident that there are clear differences in the degree of the grain refinement of the specimens pre-deformed at 980 and $820^{\circ} \mathrm{C}$. Figure $4 \mathrm{e}$ displays the clustering and colony arrangement of the refined grains, showing a homogeneous distribution. Meanwhile, grains in the white part with a pancaked morphology were comprised of equiaxed subgrains marked by the aqua arrows, representing the deformed pro-eutectoid ferrite. This is in agreement with the published results by Zhang et al. [26]. The equiaxed subgrains in the pancaked grains are produced by dynamic recovery (DRV) of the pro-eutectoid ferrite [25].

When the pre-deformation temperature decreased to $820^{\circ} \mathrm{C}$, the development of ultrafine grains was relatively limited, as indicated in Fig. 3f. Also, enormous substructures were generated in the grains of the white part rather than the anticipated dynamically formed structures, which indicated that the DRV process was well developed. Among the grains in the white parts, some large grains with many LAGBs but devoid of the equiaxed subgrains should represent the deformed austenite, which had phase-transformed to the bainite microstructure during water quenching. These were marked by aqua ellipses in Fig. $4 \mathrm{f}$. The remaining relatively small grains consisting of many subgrains produced by DRV represented the pro-eutectoid ferrite, as marked by aqua arrows in Fig. 4f. This distinction can be related to the extremely higher stacking fault energy of ferrite, which causes the dislocation 

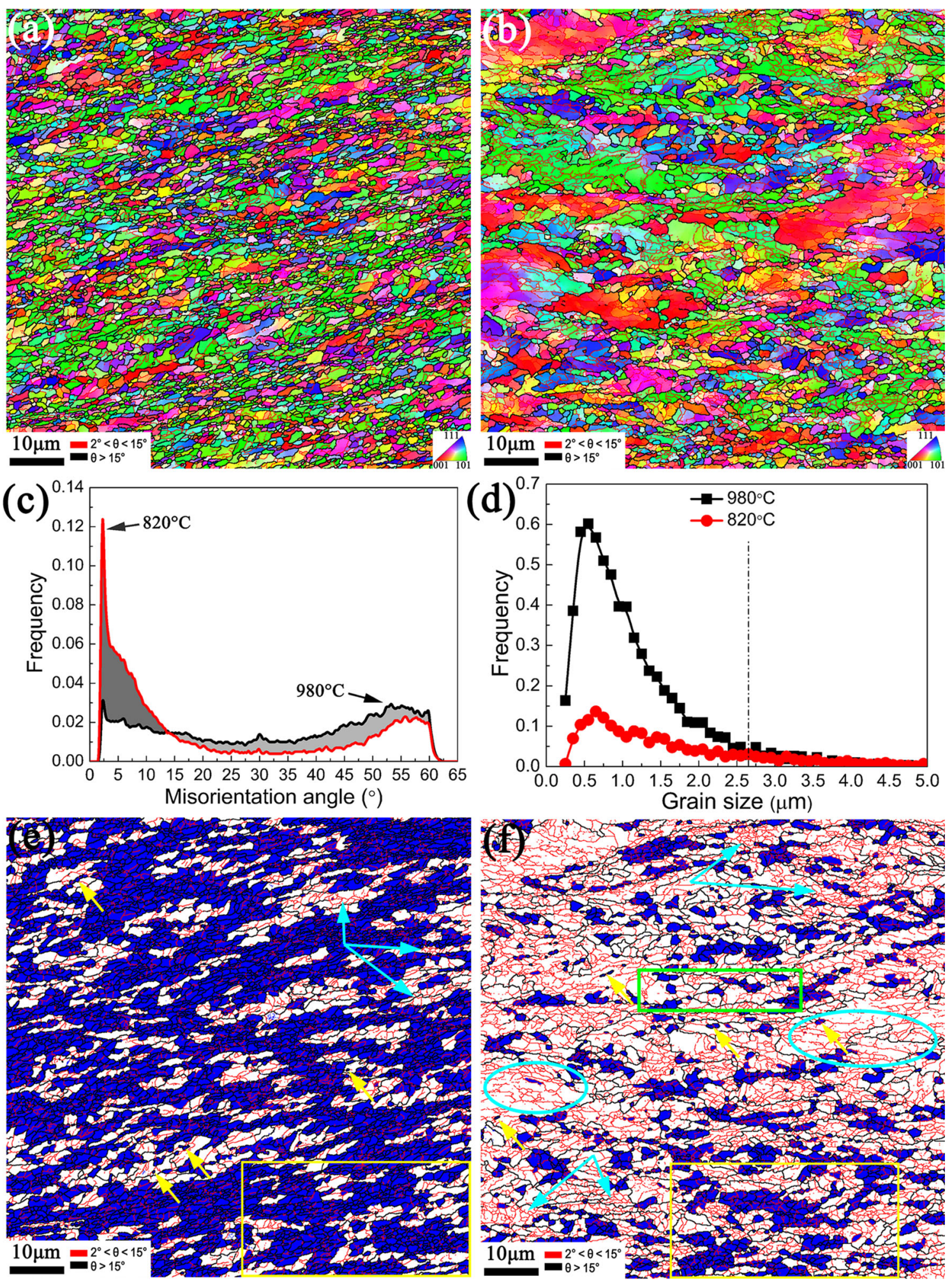

Fig. 4 IPF maps of the specimen deformed at: a $980{ }^{\circ} \mathrm{C}$, b $820^{\circ} \mathrm{C}$. c Misorientation distribution map. d Grain size distribution map. Grain size maps of 0-2.7 $\mu \mathrm{m}$ in Fig. 3a of the specimen deformed at: e $980{ }^{\circ} \mathrm{C}, \mathbf{f} 820^{\circ} \mathrm{C}$. In Fig. $4 \mathbf{e}, \mathbf{f}$ the yellow squares were selected and enlarged in Fig. 5, and the aqua and yellow arrows indicated the pro-eutectoid ferrite and DIF grains, respectively. In Fig. 4f, the green square was selected and enlarged in Fig. 6, and the aqua ellipse indicated the bainite structure 
multiplication and tangle resulting in the formation of the dislocation cell structure [28]. In contrast, for the case of the undercooled austenite deformed in the intercritical zone, the DIFT consumed most of the deformation stored energy. Thus, the remaining austenite without DIFT contained several deformation bands that were finally transform to bainite during quenching.

Furthermore, the volume fraction of the pro-eutectoid ferrite was 39 and $22 \%$ for the specimens pre-deformed at 980 and $820^{\circ} \mathrm{C}$, respectively, before ID; this was also measured by the Image-Pro Plus software. In contrast, the volume fractions of the grains that were smaller than $2.7 \mu \mathrm{m}$ were 66 and $23 \%$ for the specimens pre-deformed at 980 and $820{ }^{\circ} \mathrm{C}$ after ID, respectively. It has been observed in Fig. 4c, d that DRV occurred for parts of the pro-eutectoid ferrite during ID. In other words, only part of the pro-eutectoid ferrite completed the cDRX process. Compared with the difference in the volume fraction between the pro-eutectoid ferrite and the grains smaller than $2.7 \mu \mathrm{m}$, the volume fraction was higher for the refined grains than the pro-eutectoid ferrite, indicating that both the DIFT and ferrite cDRX processes took place. Considering the results of the critical stress analysis, this confirmed that the DIFT preceded the cDRX based on predeformation at $980{ }^{\circ} \mathrm{C}$. In contrast, the cDRX of pro-eutectoid ferrite preferentially occurred during the ID process with pre-deformation at $820^{\circ} \mathrm{C}$.

These results occurred for the following reasons. It is evident that the onset of dynamic transformation accelerates with the decrease in the austenite grain size [9, 12, 29]. Consequently, the large original austenite grains of the specimens pre-deformed at $820^{\circ} \mathrm{C}$ limited the DIFT, hence leading to the reduction in the DIF percentage. At the same time, the finer initial grains of ferrite improved the DRX process, thereby resulting in the refinement of the final microstructure [30]. As such, for the specimens of predeformed at $820^{\circ} \mathrm{C}$, the occurrence of DIFT of austenite was reduced, whereas the occurrence of ferrite cDRX tended to increase. As a result, the cDRX process preferentially occurred in the specimens pre-deformed at $820^{\circ} \mathrm{C}$. In contrast, the grain size of the original austenite was markedly smaller in the specimens pre-deformed at $980{ }^{\circ} \mathrm{C}$ than at $820^{\circ} \mathrm{C}$, which promoted the DIFT. Another main reason is the increased degree of undercooling as an effective way for accelerating the DIFT and promoting the grain refinement [20]. Moreover, the presence of the $a$ / $r$ interface, which provides more nucleation sites for DIFT, can accelerate the phase transformation process $[9,26]$. In addition, the cDRX process can also be promoted by the $a$ / $r$ interface through the pinning effect on the ferrite subgrain boundaries [19]. The content of $a / r$ interface was greater in the specimen pre-deformed at $980{ }^{\circ} \mathrm{C}$ than at $820{ }^{\circ} \mathrm{C}$ because of the higher percentage of the pro-eutectoid ferrite in the $980{ }^{\circ} \mathrm{C}$ specimen. Therefore, in the case of the pre-deformation at $980{ }^{\circ} \mathrm{C}$, both the DIFT and cDRX processes were well developed during ID even though the DIFT process occurred preferentially.

Particularly, the intragranular nucleation of the DIF transformed on the deformation bands was observed in the two specimens, as marked by the yellow arrows in Fig. 4e, f.

\subsection{Mechanism of Grain Refinement}

To determine the cDRX mechanism during ID, the enlarged grain average misorientation (GAM) maps of EBSD were used and are presented in Fig. 5a, b. The GAM is measured by averaging the intragranular misorientation angles among all adjacent pixels and represents the gradient of the inside grain-averaged orientation; it can characterize both the local lattice rotation of subgrains and the defect densities within the grains [31-33]. In this study, the GAM values from small to large corresponded to the rainbow color scale from blue to red. The critical misorientation for GAM measurement was $5^{\circ}$.

It should be noted that in Fig. 5a, b different subgrains with ultrafine size were enclosed simultaneously by the LAGBs and HAGBs. In addition, the various colors within grains represented the gradient change of GAM, which coexisted inside the grains and between the adjoining grains or subgrains.

Commonly, the generation of new grains through cDRX can be carried out by two mechanisms [30, 34]. The first one is the absorbing dislocation mechanism. The subgrain boundaries incessantly accumulated the dislocations into LAGBs that are subsequently converted to HAGBs at the relatively high deformation temperature. In this case, an increase in the grain misorientation is considered to be homogeneous, because the grains were subdivided into equiaxed cells by plastic deformation [34, 35]. The second one is the subgrain rotation mechanism. The subgrain lattices are gradually rotated adjacent to the grain boundaries, and this is accompanied by the sub-boundary or HAGBs migration. Due to this mechanism, the sizes of the subgrains are found to be similar to the sizes of the adjacent refined grains [36, 37]. One common feature of the two mechanisms is that a portion of grains is partially bounded by the HAGBs and LAGBs [34-36].

\subsubsection{Absorbing Dislocation Mechanism of CDRX}

As illustrated in Fig. 5a, for the pro-eutectoid ferrite grains in the white part, some equiaxed subgrains were distributed along the interface and had a similar size as the new ultrafine grains nearby (marked by the yellow arrows). Such evidence was similar to the cDRX characteristic by 

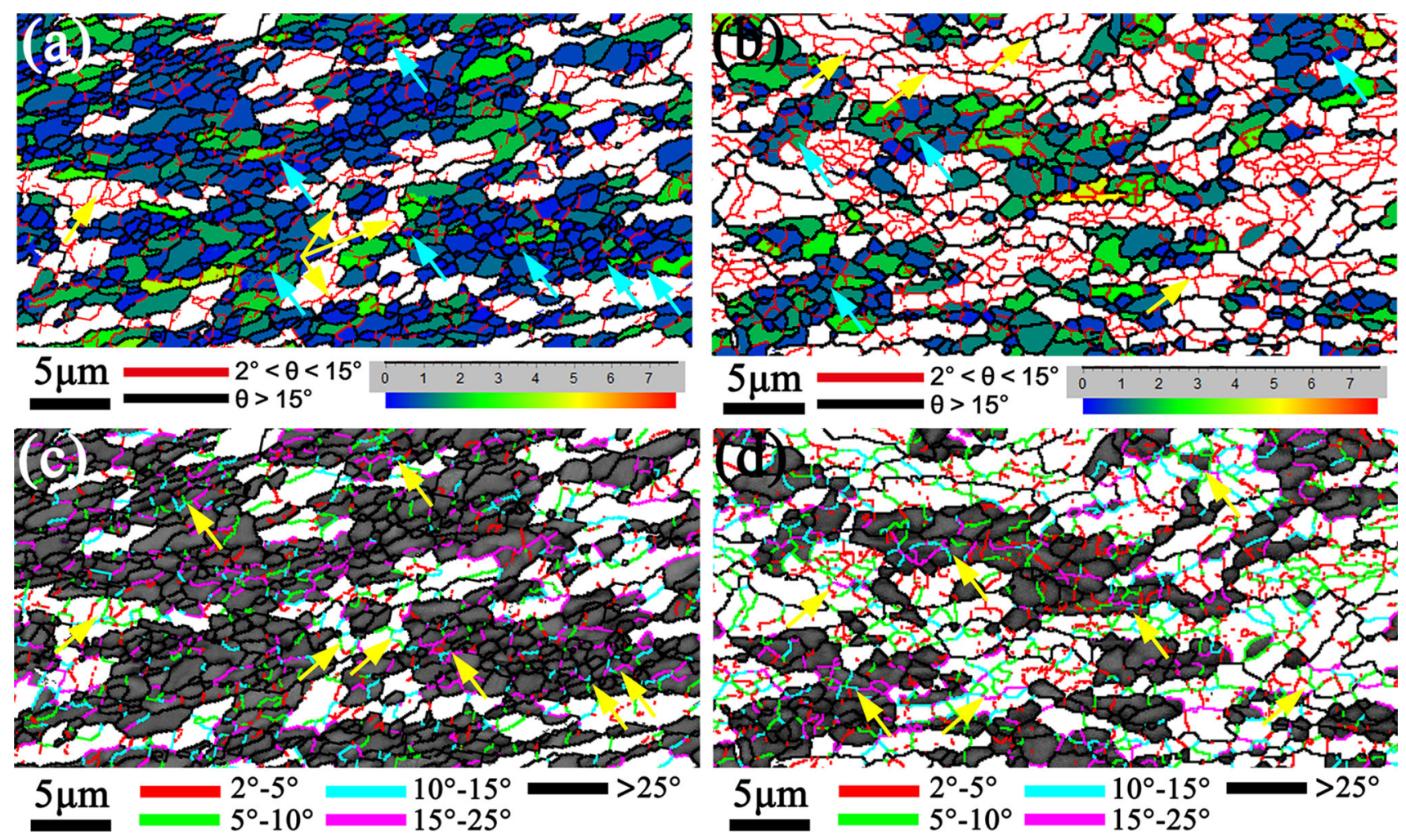

Fig. 5 Enlarged grain average misorientation (GAM) maps and enlarged band contrast (BC) maps marked by the yellow rectangle in Fig. 3b, c of the specimens pre-deforming at: a, $\mathbf{c} 980{ }^{\circ} \mathrm{C}, \mathbf{b}, \mathbf{d} 820{ }^{\circ} \mathrm{C}$, respectively

the subgrain rotation mechanism. In the refined grains colony, some of the grains were subdivided by LAGBs into an equiaxed shape and ultrafine size accompanied by the conversion of GAM (marked by the aqua arrows). Interestingly, these subgrains also had a similar size as the adjoining grains enclosed by HAGBs, which was in agreement with the absorbing dislocation mechanism of cDRX.

Additionally, Fig. $5 \mathrm{c}$ exhibits the band contrast map combined with the grain boundary map, which shows the misorientation variation and dispersion of the grain boundaries from $2^{\circ}$ to $25^{\circ}$. A progressive increase in misorientations occurring both within the refined grains colony and along the pancaked grain boundaries was observed (marked by the yellow arrows). It presented the progressive and uniform increase in the subgrain misorientation from LAGBs turning to HAGBs, which confirmed the occurrence of cDRX through the absorbing dislocation mechanism.

In contrast, as presented in Fig. 5b, the subgrains with an ultrafine size had a more observable gradient in GAM among the refined grains (marked by the aqua arrows), indicating that the cDRX process was underway. Meanwhile, the grains in the white part had enormous subgrains, suggesting the occurrence of DRV partly instead of the cDRX process. Hence, only a portion of the grains took part in the DIFT and cDRX based on the deformation at $820{ }^{\circ} \mathrm{C}$ followed by ID, whereas most of the deformation energy had been stored in the remaining grains in the form of DRV. Meanwhile, the subgrain rotation mechanism of cDRX was also observed and was marked by the yellow arrows.

Figure $5 \mathrm{~d}$ displays the band contrast map in conjunction with the grain boundary map of the specimen undergoing pre-deformation at $820^{\circ} \mathrm{C}$; this is similar to the situation in Fig. $4 c$, in which the absorbing dislocation mechanism of cDRX is also evident (marked by the yellow arrows).

It should be mentioned that some refined grains were elongated and contained LAGBs, which were formed without a complete cDRX during ID. This feature was also observed in the experiment conducted by Eghbali [24]. At the same time, there were several elongated grains without LAGBs, which should be the deformed DIF grains according to the result reported by Zhang et al. [26].

\subsubsection{Subgrain Rotation Mechanism of cDRX}

For a further investigation of the subgrain rotation mechanism of cDRX, a representative group of grains was selected from the specimen pre-deformed at $820{ }^{\circ} \mathrm{C}$; this is marked in Fig. $4 \mathrm{~d}$ by the green rectangle. These large grains with pancaked morphology represented the pro- 
(a)

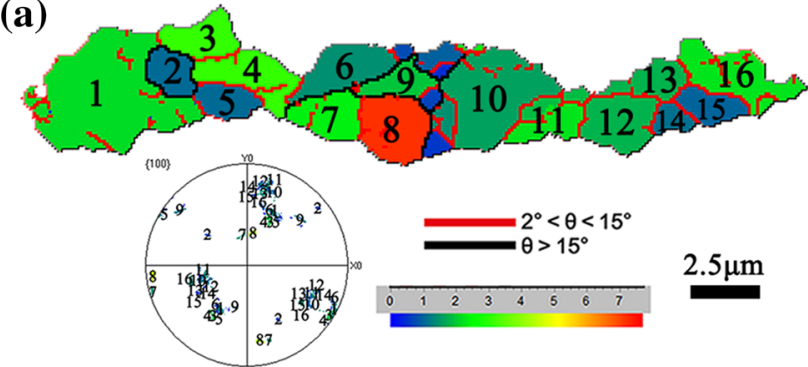

(b)

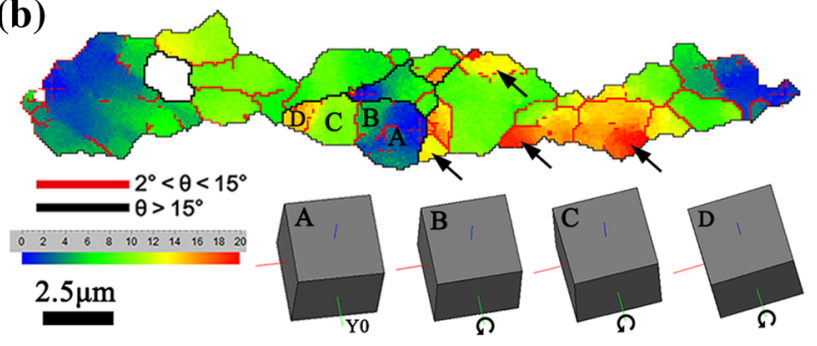

(c)

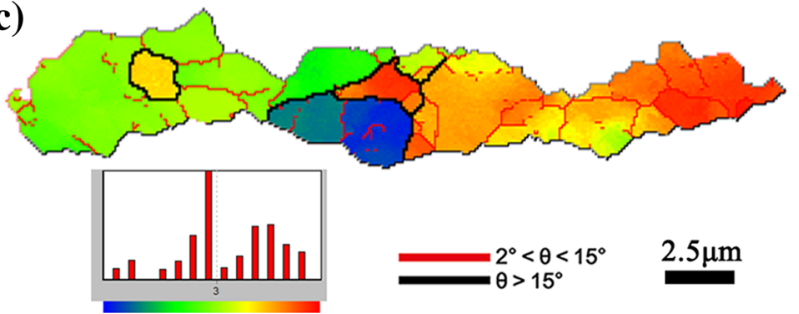

Fig. 6 One-group grains representing the pro-eutectoid ferrite selected from the specimens deformed at $820^{\circ} \mathrm{C}$ marked by green rectangles: a GAM map and corresponding $\{100\}$ pole figure, b texture component map with maximum $20^{\circ}$ deviation and $3 \mathrm{D}$ crystal orientation maps of subgrains A-D, $\mathbf{c}$ Taylor factor map with Taylor factor distribution eutectoid ferrite due to their large GAM values as well as extensive subgrains, which was discussed before. The group contained four grains. (The subgrains or grains were marked by numbers $1-6,7-8,9$ and $10-16$, respectively.) Then, as shown in the $\{110\}$ pole figure displayed in Fig. $6 \mathrm{a}$, the subgrains that belong to the same grain shared the similar orientations. The misorientations within the grains of the two groups of grains demonstrated by the change in the GAM indicated that the grain misorientations were gradually converted along the grain boundaries. Therefore, the subgrains had similar orientations but different misorientations with the adjacent matrix, indicating the lattice rotation during cDRX.

It is well known that the grain orientation can be characterized by a pair of rotation axis and angle. If the subgrains have the same rotation angles but different rotation axes, misorientations between the subgrains can be acquired without lattice rotation. Therefore, the texture component function of EBSD was used to investigate the grain rotation mechanism of cDRX. This function defines a specific orientation within the grain as a reference orientation (marked by the cross symbol in Fig. 6b). Thus, the crystal rotation of subgrains within the grains can be revealed based on the color differences, as presented in Fig. 6b. It is also demonstrated that the subgrains A-D shared the same rotation axis as observed by the 3D crystal orientation maps (bottom of Fig. 6b). This corresponded to the color gradation and directly illustrated that the subgrains formed through a progressive crystal rotation. At the same time, most of the larger deviations occurred along the
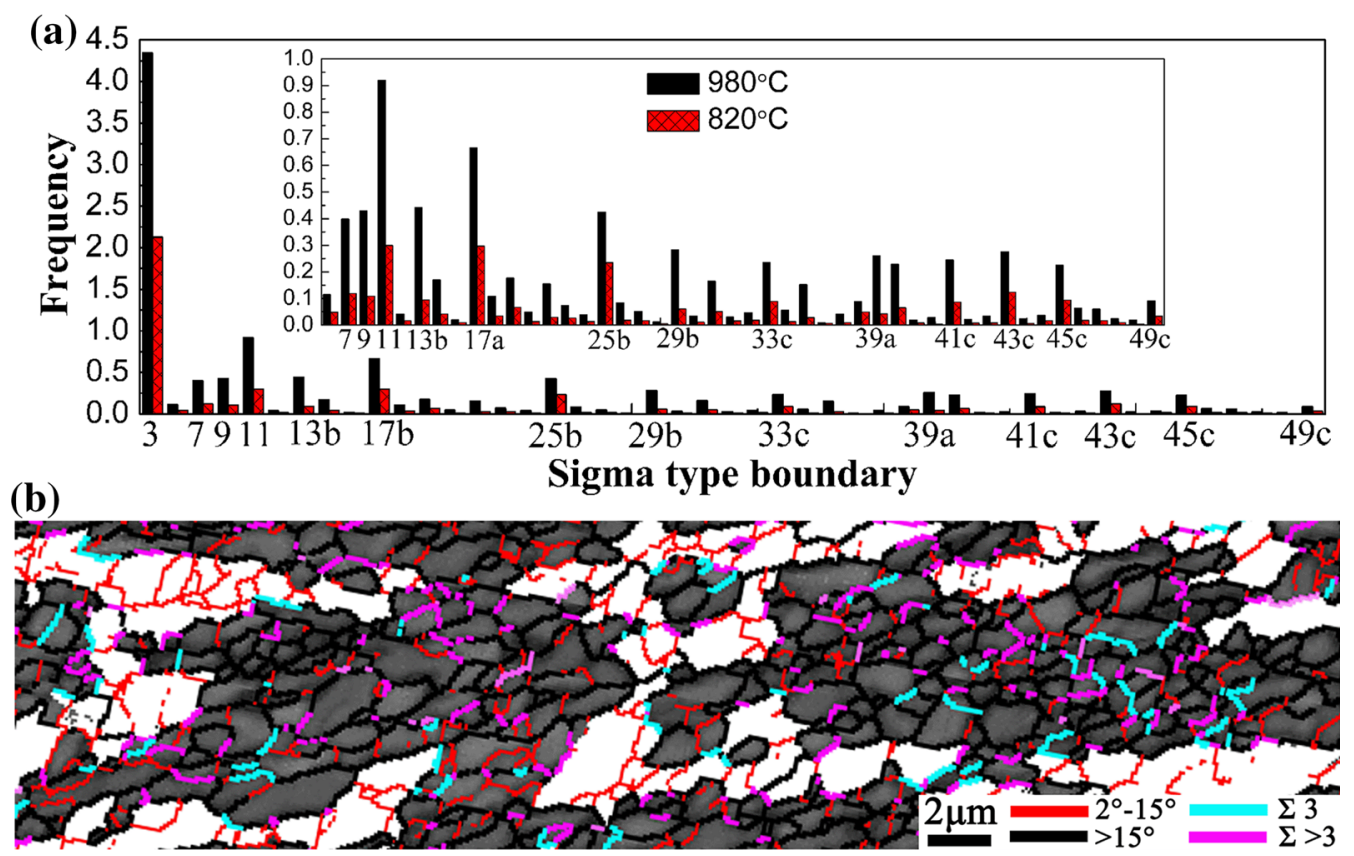

Fig. 7 a CSL boundaries distribution. b Band contrast map combined with CSL boundaries map of the specimen pre-deformation at $980{ }^{\circ} \mathrm{C}$ 
grain boundaries and were enclosed partly by LAGBs and partly by HAGBs (marked by the black arrows), which was consistent with the feature of the cDRX by the subgrain rotation mechanism.

Figure $6 \mathrm{c}$ shows the Taylor factor map and the Taylor factor distribution of the typical grains. The Taylor factor demonstrates the relationship between the yield stress and orientation in metals and can be used to analyze the level of plastic deformation [38]. Grains that easily slip and deform have a low Taylor factor, as shown in blue in the Taylor factor map. The grains that require a degree of rotation in order to slip have a moderate Taylor factor and are indicated in green. The third type of grains with a high Taylor factor is displayed in orange, which hardly rotates to produce the appropriate slip system. Therefore, it is evident that the subgrains in the left grain had to continuously deform to complete the cDRX process. Meanwhile, the subgrains in the middle grains could rotate easily to increase misorientation under enduring deformation and then newly refined grains would be generated. In contrast, the subgrains in the right grain had a high resistance to deformation. Thus, they only achieved the DRV process. These results demonstrated one of the reasons why the DRV was well developed in the specimen pre-deformed at $820{ }^{\circ} \mathrm{C}$.

Figure 7a shows the distribution of the coincident site lattice (CSL) boundaries in the specimens. The percentage of CSL boundaries was significantly higher in the specimen pre-deformed at $980{ }^{\circ} \mathrm{C}$ than at $820^{\circ} \mathrm{C}$, especially the $\Sigma 3$ boundary. Subsequently, a large number of CSL boundaries were formed in the colony of the refined grains, as shown in Fig. 7b. It has been reported that some special boundaries, such as $\Sigma 3, \Sigma 5, \Sigma 9$ and $\Sigma 11$, play an important role in DRX [39]. The formation of $\Sigma 3$ - and $\Sigma 11$-type boundaries that have low energy and low mobility decreases the distortion energy through grain rotation during deformation, which benefits the cDRX [39]. Also, some other large $\Sigma$ boundaries with high mobility can also promote the cDRX by introducing grain boundary dislocations [40]. Therefore, the effect of the CSL boundaries on the cDRX process needs further investigation.

\section{Conclusions}

1. In this study, ultrafine grains of $\sim 1.0 \mu \mathrm{m}$ with uniform distribution were fabricated through pre-deformation in RZ followed by ID.

2. A refined, equiaxial and homogeneous structure based on pre-deformation in RZ was found to be beneficial for fabricating a uniform ultrafine grain. Under predeformation in NRZ, the microstructure consisted of a high percentage of large original austenite and small pro-eutectoid ferrite. After the ID, only a portion of grains achieved the microstructural reconstitution, whereas the remaining grains were filled with a wellextended substructure through the DRV process.

3. The ultrafining mechanism through pre-deformation followed by ID was a result of the combined action of the DIFT and pro-eutectoid ferrite cDRX.

4. The cDRX process during ID was achieved by the subgrains rotation adjacent to the interface and subgrains progressively accumulated dislocations.

Acknowledgement This work was financially supported by the National Key Research and Development Program of China (Grant No. 2017YFB0304901).

\section{References}

[1] X.L. Li, C.S. Lei, X.T. Deng, Y.M. Li, Y. Tian, Acta Metall. Sin. (Engl. Lett.) 30, 1067 (2017)

[2] K.S. Kim, L.X. Du, C.R. Gao, Acta Metall. Sin. (Engl. Lett.) 28, 692 (2017)

[3] B. Li, Q.Y. Liu, S.J. Jia, Y. Ren, B. Wang, Scr. Mater. 152, 132 (2018)

[4] M.H. Cai, H.S. Huang, H.J. Pan, H.J. Pan, S.H. Sun, S.H. Sun, H. Ding, P. Hodgson, Acta Metall. Sin. (Engl. Lett.) 7, 1 (2017)

[5] R. Song, D. Ponge, D. Raabe, J.G. Speer, D.K. Matlock, Mater. Sci. Eng. A 441, 1 (2006)

[6] I. Tamura, H. Sekine, T. Tanaka, C. Ouchi, Thermomechanical Processing of High-strength Low-Alloy Steels, 1st edn. (Butterworth \& Co, Boston, 1988)

[7] S. Torizuka, E. Muramatsu, S.V.S. Narayana Murty, K. Nagai, Scr. Mater. 55, 751 (2006)

[8] Y. Okitsu, N. Takata, N. Tsuji, Scr. Mater. 60, 76 (2009)

[9] H. Dong, X.J. Sun, Curr. Opin. Solid State Mater. Sci. 9, 269 (2005)

[10] C. Ghosh, C. Aranas Jr., J.J. Jonas, J. Jonas Prog. Mater Sci. 82, 151 (2016)

[11] Y.Q. Weng, Ultra-Fine Grained Steels, 1st edn. (Springer, Berlin, 2003)

[12] N. Park, S. Khamsuk, A. Shibata, N. Tsuji, Scr. Mater. 68, 611 (2013)

[13] S. Torizuka, K. Nagai, Mater. Sci. Forum 426-432, 4573 (2003)

[14] Y.H. Bae, J.S. Lee, J.K. Choi, W.Y. Choo, S.H. Hong, Mater. Trans. 45, 137 (2004)

[15] S.Y. Shin, G. Gong, S. Kim, S. Lee, Metall. Mater. Trans. A 38, 1012 (2007)

[16] E.I. Khlusova, A.A. Kruglova, V.V. Orlov, Met. Sci. Heat Treat. 49, 549 (2007)

[17] B. Hwang, C.G. Lee, S.J. Kim, Metall. Mater. Trans. A 42, 717 (2011)

[18] A.V. Shmakov, V.M. Salganik, S.V. Denisov, A.R. Gareev, D.O. Pustovoitov, Steel Trans. 42, 148 (2012)

[19] R.Z. Wang, T.C. Lei, Scr. Mater. 31, 1193 (1994)

[20] S.C. Hong, S.H. Lim, K.J. Lee, D.H. Shin, K.S. Lee, ISIJ Int. 43, 394 (2003)

[21] J. Majta, A.K. Zurek, Int. J. Plast 19, 707 (2003)

[22] S.Y. Ok, J.K. Park, Scr. Mater. 52, 1111 (2005)

[23] B. Eghbali, A. Abdollah-zadeh, Scr. Mater. 53, 41 (2005)

[24] B. Eghbali, Mater. Sci. Eng. A 527, 3407 (2010)

[25] A. Karmakar, S. Svivsprasad, S.K. Nath, R.D.K. Misra, D. Chakrabarti, Metall. Mater. Trans. A 45, 2466 (2014) 
[26] C.L. Zhang, M.M. Zhang, T.T. Guo, J.F. Yang, Y.T. Kong, D.Y. Cai, Q. Li, Mater. Charact. 113, 10 (2016)

[27] T. Sakai, A. Belyakov, R. Kaibyshev, H. Miura, J.J. Jonas, Prog. Mater Sci. 60, 130 (2014)

[28] J.J. Jonas, C. Ghosh, X. Quelennec, V.V. Basabe, ISIJ Int. 53, 145 (2013)

[29] N. Park, S. Khamsuk, A. Shibata, N. Tsuji, Scr. Mater. 68, 611 (2013)

[30] L. Sun, K. Muszka, B.P. Wynne, E.J. Palmiere, Scr. Mater. 64, $280(2011)$

[31] S. Zaefferer, P. Romano, F. Friedel, J. Microsc. 230, 499 (2008)

[32] S.I. Wright, M.M. Nowell, D.P. Field, Microsc. Microanal. 17, $316(2011)$
[33] H. Zhao, B.P. Wynne, E.J. Palmiere, Mater. Charact. 123, 339 (2017)

[34] K. Huang, R.E. Loge, Mater. Des. 111, 548 (2016)

[35] S. Gourdet, F. Montheillet, Acta Mater. 51, 2685 (2003)

[36] P. Cizek, Acta Mater. 106, 129 (2016)

[37] M. Bestmann, D.J. Prio, J. Struct. Geol. 25, 1597 (2003)

[38] M.A. Mohtadi-Bonab, J.A. Szpunar, R. Basu, M. Eskandari, Int. J. Hydrogen Energy 40, 1096 (2015)

[39] H.T. Yan, H.Y. Bi, X. Li, Z. Xu, J. Mater. Process. Technol. 209, 2627 (2009)

[40] F.J. Humphreys, M. Hatherly, Recrystallization and Related Annealing Phenomena, 2nd edn. (Elsevier, New York, 2004) 